\title{
Identifying and Addressing Stakeholder Interests in Design Science Research: An Analysis Using Critical Systems Heuristics
}

\author{
John R. Venable \\ School of Information Systems, \\ Curtin University of Technology, \\ Perth, Western Australia
}

\begin{abstract}
This paper utilises the Critical Systems Heuristics (CSH) framework developed by Werner Ulrich to critically consider the stakeholders and design goals that should be considered as relevant by researchers conducing Design Science Research (DSR). CSH provides a philosophically and theoretically grounded framework and means for critical consideration of the choices of stakeholders considered to be relevant to any system under design consideration. The paper recommends that legitimately undertaken DSR should include witnesses to represent the interests of the future consumers of the outcomes of DSR, i.e., the future clients, decision makers, professionals, and other nonincluded stakeholders in the future use of the solution technologies to be invented in DSR. The paper further discusses options for how witnesses might be included, who should be witnessed for and obstacles to implementing the recommendations.
\end{abstract}

Keywords: Critical Systems Heuristics, Design Science Research, Stakeholder Analysis, Design Goals, Critical Research, Ethics, Participation.

\section{Introduction}

Design Science Research (DSR) has recently received much attention in the Information Systems literature. MIS Quarterly, the IS field's flagship publication, has published a seminal article (Hevner et al, 2004) and a special issue on DSR. Three international conferences on the topic have now been held focusing on the topic (Hevner and Chatterjee, 2006, Chatterjee and Rossi, 2007, Baskerville and Vaishnavi, 2008) with a fourth to be held soon. Web pages on the topic have been created and incorporated into IS World Net (Vaishnavi and Kuechler, 2005).

DSR is a paradigm or stream of IS research that aims to help solve important human, organisational, and business problems through the invention, design, and development of new "solution technologies" (Venable, 2006a). DSR has been touted by many (e.g. March and Smith, 1995, Hevner et al 2004, Venable 2006a, 2006b) as an important stream of research for improving the relevance of IS research (or addressing what Robey and Markus (1998) called the "relevance crisis" in the IS field). 
One motivation for the recent emphasis on DSR as a research approach is that design as an activity has been viewed by many in the IS field (particularly in North America) as practice, rather than research, and therefore illegitimate as a research activity. Proponents of DSR attempt to legitimate its practice (and publishability) both by noting its relevance (as above) and also by distinguishing Design Science Research from (ordinary) design practice. The key distinguishing characteristic is that DSR attempts to solve problems that are general in nature, with generic solutions that can be applied in multiple situations. Design practice, on the other hand, solves particular, situated problems with particular stakeholders. Another distinguishing characteristic is that in DSR, outcomes are published, while in ordinary design practice they are not.

While the term "Design Science Research" (often just "Design Science") is relatively new, the roots of its practice go far back in IS research practice and tradition, arising out of computer science and software engineering. What is new in DSR is the newfound care with which the field considers and reflects upon how DSR should be conducted to improve its rigour and relevance. A growing number of papers have made recommendations about how DSR should be conducted, how its results should be communicated, and standards for acceptable quality of DSR (Nunamaker et al, 1991, Walls et al, 1992, March and Smith, 1995, Hevner et al, 2004, Vaishnavi and Kuechler, 2005, Venable, 2006a, 2006b, Baskerville et al, 2007, Gregor and Jones, 2007). These lessons, recommendations and standards are also potentially applicable to research approaches used in computer science and software engineering.

However, there remain important questions to be asked about the goals and ethical practice of DSR. Baskerville et al (2007) note that the goals to be addressed by DSR depend on the view of the problem to be solved, and that there are multiple such views. Cranefield and Yoong (2007) in particular have asked the question "To whom should Information Systems Research be relevant?" (also asked by Keen, 1991). They develop an "Ecology of IS Practice" (i.e. potential stakeholders in IS Research) including levels ranging from the individual up to society as a whole. Furthermore, at a recent panel at ECIS on the promise of DSR to improve the relevance of IS Research (Pries-Heje et al, 2007), Prof Michael Myers (then AIS president) noted the absence of ethics as a concern in the standards for the conduct of DSR. Unfortunately, the existing literature on DSR does not address these concerns.

Critical Research takes an ethical stance on both research and practice (Stahl, 2008). Stahl (2008) defines critical research as "research characterized by an intention to change the status quo, overcome injustice and alienation, and promote emancipation" (p. 139). Most DSR authors do not take a stance with respect to this intention, by default leaving the intention up to the researcher. Where guidance is provided on what kinds of goals should be addressed, these are explicitly supposed to align with "business strategy" (e.g. Hevner et al, 2004, figure 1) or "business needs" (e.g. Hevner et al, 2004, figure 2). Indeed, much of the published DSR literature could be characterised (and criticised) as serving the interests of "efficiency, rationalization and progress", which are viewed as increasing "social control and domination" (Cecez-Kecmanovic et al, 2008, p. 123). Cecez-Kecmanovic et al, (2008) further note that Critical Research in IS should also investigate "the practice, purpose, implications, and institutional constraints under which” IS research operates (p. 123), presumably including DSR in IS. 
This paper partially addresses the above concerns by critically examining the issue of stakeholders and design goals in DSR. The identification, selection and inclusion of stakeholders and their participation in determining goals are (or should be) key issues in both design practice and in DSR. Failure to consider and include possible stakeholders in DSR (or in design practice) can be viewed as a form of systematic communication distortion, resulting in the loss of communicative action in favour of instrumental action (Habermas, 1983). Such communication distortion is perpetrated by IS Design Science researchers in the interest of business (managers and owners). It is potentially at the expense of others, by preventing them from representing their own interests (e.g., their own emancipation).

But, how can and should we judge which stakeholders to include and how to avoid such distortion? What about DSR (as opposed to design practice) affects our answer to this question? What guidance should we give to the Design Science Researcher? To analyse and answer these questions, this paper employs Critical Systems Heuristics (CSH) (Ulrich, 1983, 1987, 2002). Werner Ulrich, who was a student of Churchman, developed CSH to provide a philosophically and theoretically grounded framework and means for critical consideration of the choices of stakeholders considered to be relevant to any system under design consideration. DSR is at a higher level than design practice, but still is confronted with issues of goals, boundaries, and stakeholders, for which CSH is a useful framework for analysis.

The next section reviews relevant IS research literature to establish a clear context for the work in this paper. The subsequent section introduces the CSH framework as published by Ulrich. Next, the paper applies the CSH framework to DSR. The paper concludes with an analysis of some implications arising from the CSH analysis of DSR.

\section{Literature Review}

Literature relevant to the topic of this paper comes from the DSR, IS relevance, and stakeholder analysis literatures. We consider each of these briefly in turn.

\subsection{Research Goals and Stakeholders in the DSR Literature}

As noted above, key papers in the DSR literature make recommendations about how DSR should be conducted, how its results should be communicated, and standards for acceptable quality (Nunamaker et al, 1991, Walls et al, 1992, March and Smith, 1995, Hevner et al, 2004, Vaishnavi and Kuechler, 2005, Venable, 2006a, 2006b, Baskerville et al, 2007).

Nunamaker et al (1991) justified system development as a research methodology (an early form of DSR in IS). They develop a multi-methodological framework for IS Research, including four major types of activity: (1) theory building, (2) experimentation, (3) observation, and (4) systems development. Of these types of activities, only (3) observation, which is concerned with observing a problem domain to get an appreciation of its circumstances, provides guidance for what problems are to be addressed. However, in describing this activity, Nunamaker et al (1991) provide no guidance about stakeholders or how one focuses on particular aspects of the problem domain.

Nunamaker et al further describe a five-step System Development Research Methodology: (1) Construct a Conceptual Framework, (2) Develop a System 
Architecture, (3) Analyse and Design the System, (4) Build the (Prototype) System, and (5) Observe \& Evaluate the System. The first step includes "state a meaningful research question." Presumably this draws on information garnered from observation (above). The only guidance provided is that the question should draw on a research problem that is "new, creative, and important in the field" (p. 98). This still leaves the question, "Important according to whom?"

Walls et al (1992) develop the concept of an IS Design Theory (ISDT), which has seven components. The main component of interest here is that of MetaRequirements, which represent the goals or contingencies to be addressed by a particular kind of solution to be designed. However, the paper provides neither a process-oriented view of DSR nor any advice about where those meta-requirements should come from or how they should be established.

March and Smith (1995) emphasise that DSR is oriented toward problem solving and that "Problems must be properly conceptualised ..." (p. 251). They identify the main research activities of build (a technology/systema), evaluate (the built technology/system), theorise (about how/why the technology/system works or not), and justify (the resulting theory). They further identify four products of DSR: representational constructs, models, methods, and instantiations. The products of DSR ate to be evaluated against criteria of value and utility. However, March and Smith do not address questions about problems, value or utility for whom or the choices of which problems should be addressed. They do not provide guidance about how problems can be "properly conceptualised".

Hevner et al (2004), like March and Smith (1995), emphasise the problem solving orientation of DSR and the main DSR activities, which they group into a cycle of Develop/Build (artifact instance and theory, respectively) and Evaluate/Justify (the same). The goals to be addressed by DSR are derived by "business needs", which are obtained from the environment, or the part of it that constitutes the "problem space". According to Hevner et al (2004),

The DSR environment or problem space "is composed of people, (business) organizations, and their existing or planned technologies. In it are the goals, tasks, problems and opportunities that define business needs as they are perceived by people within the organization. ... Together these define the business need or 'problem' as perceived by the researcher. Framing research activities to address business needs assures research relevance." (Hevner et al, 2004, p. 79)

Clearly, Hevner et al (2004) acknowledge that problems are perceived (by various stakeholders). However, it can also be seen that according to Hevner et al (2004), DSR should serve the needs of business organisations (as a whole). For example, in describing their second guideline (problem relevance) for evaluating DSR projects or publications, they note that the main goal or business need to be addressed in DSR is profit maximisation. They are also quite clear about the stakeholders that they see as relevant when they state the following.

"The relevance of any design science research effort is with respect to a constituent community. For IS researchers, that constituent community is the practitioners who plan, manage, design, implement, operate, and evaluate information systems and those who plan, manage, design, implement, operate and evaluate the technologies that enable their development and implementation.” (Hevner et al, 2004, p. 85) 
The needs of various other stakeholders are therefore not addressed by Hevner et al (2004). Further, despite their recognition of the perceived nature of problems, they provide no guidance about how one should identify who should determine, represent or provide those needs to the researcher.

Vaishnavi and Kuechler (2004), in their Design Research website on AIS World, describe various aspects of DSR, including its philosophical foundations, its outputs, and a general methodology for DSR. The methodology contains five steps (awareness of problem, suggestion, development, evaluation, and conclusion), with feedback loops from later steps to earlier steps. Of these, awareness of problem is relevant to design research goals and stakeholders.

"Awareness of Problem: An awareness of an interesting problem may come from multiple sources: new developments in industry or in a reference discipline. Reading in an allied discipline may also provide the opportunity for application of new findings to the researcher's field. The output of this phase is a Proposal, formal or informal, for a new research effort." (Vaishnavi and Kuechler, 2004, n.p.)

From this it can be seen that Vaishnavi and Kuechler (2004) are open to input from different stakeholders (not just business organisations or IS practitioners), but provide no guidance for what sorts of goals DSR should pursue or how to select appropriate stakeholders.

Venable (2006a) explicitly recognises and emphasises the perceived nature of problems and that different stakeholders (and IS Design Science Researchers) may have different perceptions of a problem space and disagreements about it. However, he does not offer any advice on how to select from among different competing views of different stakeholders; he only advises that Design Science Researchers therefore need to be precise in their statements about what problem or problems they are trying to solve in any particular piece of DSR so as to avoid misunderstandings.

Baskerville et al (2007) also recognise the perceived nature of problems. However, their concern is with the evaluation of designed artifacts and IS Design Theories. The import of the perceived nature of problems is that evaluation results are different depending on the goals and interests of those involved in the evaluation (and in the determination of the original problem formulation). They also do not provide any guidance about selection of stakeholders and their interests or in goals or problems to be solved, except to suggest the use of soft methods, such as Soft Systems Methodology (SSM) (Checkland, 1981, Checkland and Scholes, 1990, Checkland and Holwell, 1998).

To summarise the DSR literature overall, some of it does not recognise (or deal at all) with the issue of different perceptions of problems; some of it recognises the perceived nature of problems, but emphasises the needs and problems of business organisations; some of it recognises the perceived nature of problems and the possibility of disagreement about what problem(s) should be solved, but is silent about how to choose. Most importantly, none of the DSR literature either considers what stakeholders (beyond "IS practitioners" or "business organisations") should be consulted about problems and how to choose among them or makes any sort of critical examination of what problem(s) should be solved or how one should arrive at that decision. 


\subsection{Research Goals and Stakeholders in the IS Relevance Literature}

A number of papers over the past few years have addressed relevance in IS Research more generally (as opposed to in IS DSR).

Benbasat and Zmud (1999) identified four aspects of relevance for IS Research: interest, applicability, currency, and accessibility. They further identified recommenddations for actions that IS researchers could take to improve relevance, including, among other things, identifying topics from IS practice, reaching agreement within the IS community on likely future issues, focusing on the future interests of key stakeholders, and providing contingency approaches for managerial action. Implicit in their discussion are stakeholders such as "IS practice", "the IS community", and management. Both "IS practice" and "key stakeholders" seem to refer to IS practitioners, especially managers. They do not acknowledge any stakeholders outside of IS practice or offer any research goals beyond those that serve IS practice.

Moody and Buist (1999, Moody, 2000) lamented the disconnect between IS research and IS practice, particularly the lack of input from IS practice to IS research about practical problems to be addressed. However, they do not provide guidance on which stakeholders within IS practice or acknowledge any research goals or stakeholders outside of IS practice.

Recently, Cranefield and Yoong (2007) directly considered the question "To whom should Information Systems Research be relevant?" Consistent with the vision for the purpose of the IS field as stated in Weber (1997) to serve "individuals, groups, organisations, societies, and nations" (p. 1), they develop an "Ecology of IS Practice" (i.e. potential stakeholders in IS Research) including various levels of increasing scope: individual (e.g., a practitioner or user), interpersonal (group), individual organisation, group of organisations (e.g. an industry), community, and society (e.g. a nation). Interestingly, they do not mention a trans-national, international or world level, although this would seem a logical extension. Very appropriately, the authors argue that "if IT practitioners, CIOs, and even CEOs are viewed as the only people to whom IS research is relevant, then IS research is unlikely to lead to improvements above the organisational level. ... The ecological perspective would reposition the IS practitioner as only one member of a richer web of consumers."

To summarise the IS relevance literature, broadly characterised, most of it considers the stakeholders and interests of IS practitioners and managers as the source of relevance and hence as the source of goals for IS Research (and hence DSR more specifically). On the other hand, Cranefield and Yoong (2007) specifically go beyond that view to propose higher levels of increasingly broad scope of stakeholders.

\subsection{Socio-technical Design and Participative/Participatory Design Literature}

Stakeholders have long been recognised in the IS Development literature. Nearly any textbook would refer to users, indirect users, system professionals, and managers as stakeholders in IS development. As noted earlier, the identification, selection and inclusion of stakeholders and their participation in determining goals are (or should be) key issues in both design practice and DSR. 
Several areas of research in IS (and other system) development have particularly emphasised participation. Socio-technical design methods, such as ETHICS (Mumford, 1983, 1996) give equal weight to performance improvement and quality of working life goals by giving workers the means to participate in setting their own design goals and designing and selecting systems that meet those goals. Participative design (e.g. Emery, 1989), coming out of the socio-technical systems/design movement, also emphasises giving users the means to participate in design. Heavily overlapping, if not interchangeable, but with a slightly different name, participatory design (e.g. Schuler \& Namioka, 1993; Kyng et al, 1997) has a long history in Scandinavia, including a series of decennial conferences at Aarhus University. Research in this stream has looked at many options for participation, including who, when, and how. See Mumford (2006) for a history of socio-technical design, which covers some of the overlap with the Scandinavian and participatory design traditions.

While there is much in this literature about how and why to achieve participation, it has a key weakness with respect to our purposes here; research in participatory design concerns how to perform (participatory) design in practice rather than how to perform DSR. I.e., participatory design defines the topic of the research rather than the method or means of doing the research. Now, it is true that many pieces of research on participative design actually are pieces of DSR, i.e. that they invent or develop new, generically applicable methods for doing participative design. They also conduct such DSR from a critical perspective, but by and large they are not systematically reflective about the stakeholders in research on participative design. Such pieces may consider who to include in the research and how, but for practical, epistemological reasons; it usually takes the research goals for granted and does not enlist stakeholders in determining them. Thus, while participatory design research may provide suggestions for methods of participation during design, it does not provide suggestions for how to critically select stakeholders in DSR.

\subsection{Stakeholder Analysis Literature}

In addition to the ISD literature, there is also a literature that looks at stakeholders in situations generally. In particular, frameworks have been identified for determining appropriate stakeholders to consider, including Qualitative Classes of Stakeholders (QCoS, Mitchell et al, 1997) and Critical System Heuristics (CSH, Ulrich, 1983, 1987, 2002).

Before considering these questions, it is worth introducing the concept of a stakeholder. Just what is a stakeholder? Checkland (1981) defines a stakeholder as a "beneficiary or victim" of an organisation, system, action or change. Freedman (1984) defines a stakeholder as "any group or individual who can affect or is affected by the achievement of the organisation's objectives." The definition that we will use here is "a person or organisation with an interest in a problematic situation or in actions taken to 'improve' the problematic situation."

As described by Cranefield and Yoong (2007), there are many things that can be stakeholders and at many levels, including: individual people, groups, neighbourhoods, organisations, institutions, societies, and even future generations. Generally we are concerned with humans, but some people consider non-human nature (animals, plants, etc.) as stakeholders (even though they cannot represent their own interests). Infants, other children, and future generations are similar in that regard. 
Another question we might consider re. stakeholders is "What is a stake (or at stake)?" A stake can be any relevant interest, benefit, or loss, including (but not limited to) money, possessions, power, legal rights or options, customs, norms, expectations, relationships to other people (social relations), activities (work or leisure), or quality of life (working or otherwise). A stake can literally be anything that someone thinks is relevant because they have an interest in it and it will or might be changed.

Mitchell et al (1997) approach the issue of stakeholders from the perspective of concern for identifying those stakeholders in companies/firms (and their decisions) who warrant managerial attention before they can interfere with organisational actions. They developed a framework entitled Qualitative Classes of Stakeholders (QCoS). This framework distinguishes three "relationship attributes", which describe the form and strength of the relationship between (putative) stakeholders and an organisation.

- Power - The stakeholder's power to influence the firm

- Legitimacy - The legitimacy of the stakeholder's relationship with the firm

- Urgency - The urgency of the stakeholder's claim on the firm

Any particular stakeholder will have at least one of these attributes, to a varying degree, and possibly (commonly) in combination. Figure 1 illustrates how these attributes can be in combination and characterizes the eight different combinations that are possible. The strongest claim for relevance as a stakeholder is to have all three (a "definitive" stakeholder in figure 1) and strongly; the weakest is to have only one attribute and weakly.

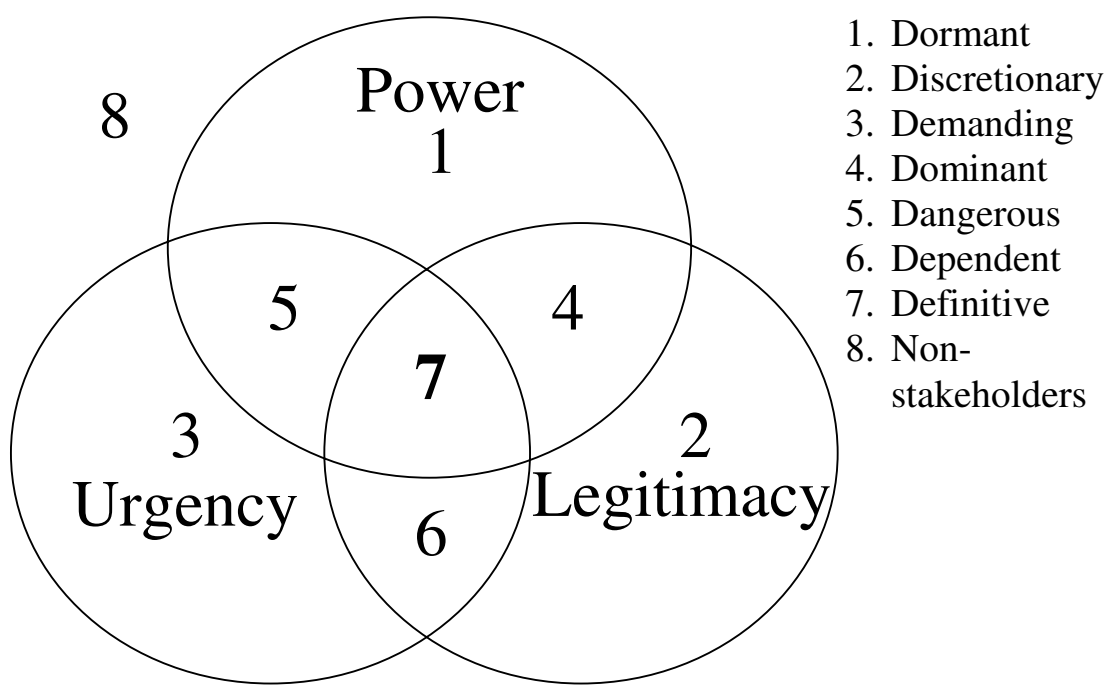

Fig. 1. Qualtitative Classes of Stakeholders (QCoS) Framework (Mitchell et al, 1997) 
The framework highlights why management ignores some stakeholders (weak, unconsidered claims). However, ignoring stakeholders can lead to lack of cooperation, resistance, and system/solution failures - as well as inappropriate systems.

While interesting and informative, QCoS can be strongly criticised from a Critical Research perspective. The means of picking stakeholders to include as ones whose needs should be addressed is rooted in an analysis of their power and status. In a nutshell, the method serves managerial interests in identifying stakeholders whose needs must be addressed in order to achieve managerial goals. Implied is the ability to ignore certain classes of stakeholders a long as the organisation has the power to overcome them. It does not seek to increase discoursive communication (Habermas, 1983) for its own sake and those of the stakeholders, but to manipulate it through instrumental action (Habermas, 1983). Thus, the method fails the critical test of advancing emancipation interests.

Critical Systems Heuristics (CSH, Ulrich, 1983), unlike QCoS, is strongly concerned with ethical interests and adopts a critical perspective. CSH is based on systems theory and has a firm philosophical grounding. Because of its critical perspective and grounding, it is the approach used in this paper. $\mathrm{CSH}$ is described in more detail in the following section.

\section{Critical Systems Heuristics (CSH)}

Ulrich $(1983,1987,2002)$ proposed and developed Critical System Heuristics in order to address a concern arising from general systems theory. That issue is that systems theory provides guidance that the scope of a system under consideration must be decided that is wide enough to prevent local decisions from causing significant problems in the larger system(s) within which the system under consideration can be considered as a component. Thus, for example, the scope of a marketing system under consideration must (should) be considered broadly enough that sales or production do not incur problems.

However, one cannot practically continue to expand and expand the scope of a system under consideration indefinitely, because one does not have the resources to do so (i.e., one cannot design the universe or consider all its potential problems). Therefore, one needs an appropriate means to guide the boundary decision - What will we consider to be within the scope of the situation and what will we exclude?

Critical Systems Heuristics (CSH - Ulrich 1983, 1987, 2002) provides a reasoned guideline (heuristic) to guide such boundary definitions. The CSH framework incorporates 12 questions for system developers (no matter what kind of system) to answer in order to define a system's boundary or scope. Figure 2 provides an overview of the framework and its concerns. The questions are grouped according to four different boundary issues, each of which has its own kind of stakeholders, the nature of their interests, and their relevance as stakeholders.

Each of the four groups in figure 2, together with the 12 questions relating to each of the 12 areas above, is described below (Ulrich 1983, 1987, 2002). 
Boundary categories Boundary issues

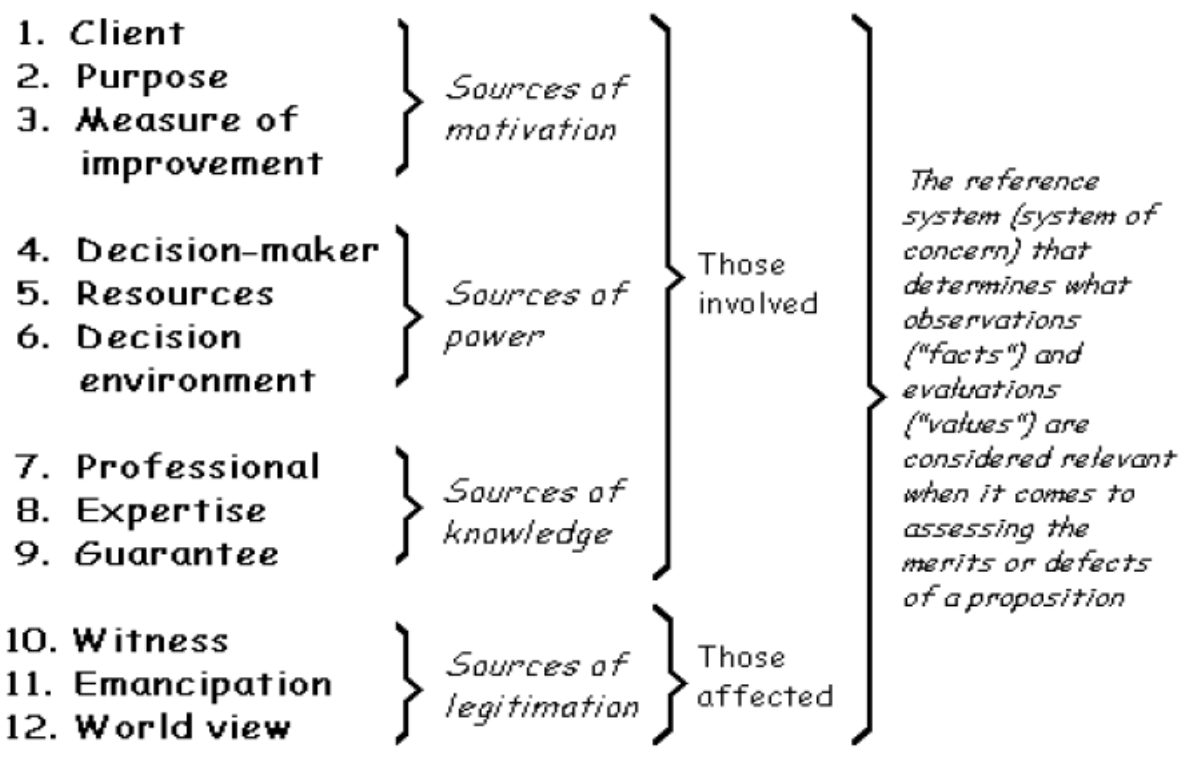

Fig. 2. Critical Systems Heuristics (CSH) Framework (Ulrich, 1983)

\section{Sources of Motivation}

1. Who is (ought to be) the client? That is, whose interests are (should be) served?

2. What is (ought to be) the purpose? That is, what are (should be) the consequences?

3. What is (ought to be) the measure of improvement? That is, how can (should) we determine that the consequences, taken together, constitute an improvement?

\section{Sources of Power}

4. Who is (ought to be) the decision-maker? That is, who is (should be) in a position to change the measure of improvement?

5. What resources are (ought to be) controlled by the decision-maker? That is, what conditions of success can (should) those involved control?

6. What conditions are (ought to be) part of the decision environment? That is, what conditions lie outside the decision-maker's control (or should lie outside, e.g., from the viewpoint of those not involved)?

\section{Sources of Knowledge}

7. Who is (ought to be) considered a professional? That is, who is (should be) involved as an expert, e.g., as a systems designer, researcher, or consultant?

8. What expertise is (ought to be) consulted? That is, what counts (should count) as relevant knowledge? 
9. What or who is (ought to be) assumed to be a guarantor of success? That is, what serves (should serve) as a guarantee that improvement will be achieved - for example, consensus among experts, the involvement of stakeholders, the experience and intuition of those involved, or political support?

\section{Sources of Legitimation}

10. Who is (ought to be) witness to the interests of those affected but not involved? That is, who voices (should voice) the concerns of stakeholders who are not involved or cannot speak for themselves, including future generations and nonhuman nature?

11. What secures (ought to secure) the emancipation of those affected from the premises and promises of those involved? That is, where does (should) legitimacy lie?

12. What worldview is (ought to be) determining? That is, what different visions of "improvement" are (should be) considered, and how are they (should they be) reconciled?

All of the above questions have critical emphasis and implications. They all exist to guide people endeavouring to make "improvements" via systemic interventions to think explicitly and critically about what perspectives and goals should guide their choices and actions. Making the choice of client and purpose explicit (rather than leaving it implicit) forces a critical perspective. Explicitly considering who will make a decision on an intervention and how to decide forces a critical perspective. Explicitly considering what will guarantee success forces critical consideration of the ability and feasibility of making change responsibly, rather than putting stakeholders at risk of going through all the effort and pain of implementing change that in the end does not work. The last three questions have a particularly strong critical appeal in considering how to accommodate the interests of those who aren't even part of the process and otherwise have no voice.

Having sketched out the basics of the CSH approach and framework, the next section applies the framework to analyse the area of Design Science Research.

\section{A Critical Systems Heuristics Analysis of Design Science Research}

In this section we apply the CSH framework to Design Science Research (DSR) in order to analyse potential difficulties and to provide guidance for the conduct of DSR. But first, we should consider why it is relevant to apply CSH to DSR.

Design Science Research is all about solving problems and making improvements. The means for doing so is to invent new or improved solution technologies (Venable, $2006 \mathrm{a}, \mathrm{b}$ ) as the means for solving (or partially solving) a class or classes of problems, possibly problems that have never been addressed or solved before. By such invention, DSR produces and disseminates knowledge about how to solve the the class of problems so that others can apply that knowledge to solving their own problems or making improvements in their own situations. Applying knowledge to solve a problem requires intervention in a system, a system that almost always has 
multiple stakeholders and interests; therefore CSH is applicable. Design Science researchers then have an opportunity (and arguably an obligation) to consider how solutions that they invent will or can be used or applied and the scope of the problem or system that they should be considering when inventing new means or technologies to solve problems. Design Science researchers also need to design the technologies, practices, and knowledge they invent so that their inventions are likely to be employed appropriately.

Before applying the CSH framework, we should also consider why DSR is different from ordinary design and what implications that may have for a CSH analysis. Why is DSR a special case of design? Why might CSH apply differently to DSR than to 'ordinary' design - i.e. to design practice?

Ordinary design, or design practice, is related to a particular, situated problem (or group of problems). It has particular stakeholders with particular interests in the problem(s) and its/their potential solution(s). On the other hand, Design Science Research should be related to a type, kind, or class of problems (an abstract problem), which has characteristics that are generalised from typical, similar problems. It is relevant to typical classes of stakeholders rather than to particular people or organisations. The scope of both the problem to be addressed by the new solution technology and of the system in which intervention is to occur is generalised from the scopes of typical problems in typical systems. The applicability of the proposed new solutions is intended for situations of that type. Therefore, the stakeholders in these future problems are hypothetical and the scope of the problem to be addressed is intentional and hypothetical as well. Furthermore, rather than actually solving the situated problems (via design practice), it only indirectly contributes to their solution by developing new forms of solution and communicating them to would-be problem solvers. Therefore, the Design Science researcher must anticipate how others will put the solutions technologies that they invent into practice; the researchers themselves (for the most part) will not apply the solutions to ordinary design practice. [Note: An exception is Action Research, which may comprise both Design Practice (and intervention) and Design Science Research.] Design Science researchers must take into account that they are one step removed from actual problem solution when designing and inventing generalised solutions. They have a responsibility to consider how the things they invent will be used and whether they will achieve appropriate ends and outcomes through their use (and not achieve inappropriate ones!).

Having identified that CSH is appropriate for Design Science Research, the next four sections analyse DSR using the CSH lens, considering in turn the roles of client, decision maker, professional, and witness and that Design Science researchers may have to answer some of the above questions for themselves based on the particular types of problems, stakeholders, and situations intended (and unintended!) to be addressed.

\subsection{The Client Role in Design Science Research}

As discussed above, the Client is the role of the person/people/organisation(s) with an interest in solving the problem, or in the case of DSR, the type of hypothetical people with potential future interest in solving problems of the particular type(s) to be 
addressed by the new solution technology. The key issues for the client role are the purpose and the measure of improvement.

One could take a very narrow view and say that it is only the Design Science Researcher who determines the purpose(s) in solving a generalised problem. Design Science researchers might be considered to be their own clients in satisfying their own curiosity and in creating publishing opportunities. One could say that the readers of the published knowledge either find the information relevant and useful or not, but the researcher has no real obligation to anticipate their needs. However, I do not find this position tenable, particularly for employees who conduct research for the public good and have an obligation to publish (without which it is not really research).

Another perspective is that the nature of the client depends on who funds the research and on whose behalf the Design Science researcher is acting. Where this is a private organisation, it may be fairly narrowly defined as the client and have key interests. However, even if the funding organisation has an important and non-public interest, if research outcomes are published for consumption by the general public as would-be problem solvers, isn't the public a client?

For DSR, then, we could broadly define the Client role as "The set of all members of the generalised class of all people or organisations who could potentially be motivated to solve instances of the generalised class of problem(s)".

But who would this actually be? Can the Design Science researcher anticipate this correctly and select client stakeholder groups accordingly? Or, should we assume that the public (or even, if taken to extreme, all of humanity) are the clients of DSR? The real issue is who determines (or is involved in determining) the purpose(s) of the Design Science Research and the associated measure(s) of improvement. These issues are considered further later in this paper.

\subsection{The Decision Maker Role in Design Science Research}

The Decision Maker role is that of the person who decides which actions will be taken to intervene in the system and make an "improvement". Typically, they are the people who fund the intervention. In the case of DSR, the direct nature of the improvement is to publish and disseminate the ideas. The key issues for the decision maker role are resources and the decision environment.

A narrow view would hold that, with academic freedom, it is the Design Science researcher who decides what research will be undertaken and what they will do. The researcher can decide what research work to do and what to publish. However, the researcher is generally paid by someone else - a public or private institution, such as a university or a research funding agency. Funding agencies in particular are only rarely concerned just with the publication. They are interested in the possibility for actual improvement and problem solving following publication through the use of the new solution technology and make funding decisions accordingly. They expect the Design Science research to consider the needs of those who will be deciding whether and how to employ the new solution technology (or not).

For DSR then, we could broadly define the Decision Maker role as "The set of all members of the generalised class of all who might need to decide whether to employ the result of the research to the solution of the generalised class of problem(s)". Again, we can consider whether we can know in advance who the actual future 
decision makers will be. It would seem that any members of the public or humanity are potential future decision makers about deploying the new solution technology.

\subsection{The Professional Role in Design Science Research}

The Professional role is that of the person with appropriate expertise, who actually takes action to intervene in a system and generate the improvement. The key issues for the professional role are expertise and what guarantees success in the intervention.

Narrowly defined, the Design Science Researcher has expertise in DSR and takes the action to generate and publish the knowledge, which is the Design Science researcher's intervention in the system called "the world".

However, DSR and especially publication is not done in isolation, so there are other involved expert roles. Reviewers (of grant applications and of publications) and editors of publications also have important professional roles in the evaluation of the DSR and outcomes before publication. Reviewers and editors must therefore have appropriate expertise in DSR.

Furthermore, one could say that the entire research community has a professional role to play in its reaction to published research, e.g. in discussion at conferences or in pointing out flaws in research (e.g. through letters to the editor) or in replicating, extending, and/or refuting published results.

But viewed in the large as including deployment of the new solution technology, professional role includes those who learn about, develop expertise in, and employ (or deploy) the solution technology. Viewed from this perspective, we could broadly define the Professional role in DSR as "The set of all members of the generalised class of all who could apply the solution technology developed in the Design Science research to the solution of an instance of the generalised class of problem(s)". Again this is potentially any member of the public or humanity.

The key issue here is what guarantees that the DSR will be successful, not just in being published (the immediate goal), but in the long-term goal of making improvement in the world, through the action of those who learn about and employ the newly invented and published solution technologies (or even old ones long after publication). In the case of DSR, there are issues of the correct appraisal of generalised organisational or other problems, the efficacy of the solutions, and of technology transfer. All of these are dependent on the expertise of the design researchers and others involved in DSR, and particularly the consideration and involvement of potential future stakeholders.

\subsection{The Witness Role in Design Science Research}

As described above, the Witness role is that of anyone who represents the interests of those who could be affected by the intervention and who are not able to represent their own interests in the intervention problem formulation, solution design and deployment process. The key issues in the Witness role are emancipation of affected parties, legitimacy of the intervention, and the appropriateness of the worldview(s) governing the intervention.

From the critical point of view, those who cannot represent their own interests need to have them represented in some legitimate way (informed and effective). In DSR, 
people are affected both directly by the DSR (by reading and employing the knowledge outcomes in the DSR publications) and indirectly by the DSR (by being affected by the employment of the new solution technologies).

Following from this, we could broadly define the Witness role in DSR as "The set of all who could represent the interests of all members of the generalised class(es) of all who would be affected by the publication and/or application of the new solution technology". Again, the whole of the public or humanity are potentially affected indirectly (most likely), or even directly (less likely).

From a critical perspective, DSR should be conducted in a way and with a worldview that the emancipation and other interests of those who are not directly involved will be legitimately represented. But how should that be done? Is it enough for the Design Science researcher to (say paternalistically or maternalistically) look after the interests of those potentially affected? These questions are considered further below.

\section{Discussion and Implications for Design Science Research}

In the broader definitions of the roles suggested above, members of the public have a direct interest and role to play in the conduct of DSR as a way of improving the state of the world by solving or making improvements on various types of problems. However, the practicality of their involvement seems unreasonable and impracticable. One cannot consult all of humanity! Furthermore, most if not all of us members of humanity would not want to be consulted by every Design Science researcher on how we might be affected by their particular DSR project!

In the narrower definitions of the roles above, the key direct participants are (1) the Design Science Researcher, (2) the employers of Design Science Researchers, (3) Research Funding Agencies who fund DSR projects, (4) Reviewers and Editors (and Publishers) of DSR results, and (5) (possibly) Governments and Regulatory Agencies. The Design Science Researcher may act in the roles of client (following his/her own interest), decision-maker (allocating their own time), professional (expert in DSR and the problem domain), and even witness (perhaps by reading literature, drawing on experience, or even imagining what effects the new solution technology might have on others). Employers may have a role in decision making about what DSR is done and how (client and decision maker roles or even witnesses for the public). For example, ethics review and approval bodies at universities may have an important role to play. Research Funding Agencies (whether public or private) can also play a decision maker role, but also a client role in setting out problems to be solved and priorities. Reviewers (both for publication and for competitive funding) and Editors play an important quality control role and are thus Professionals, collaborating (in some sense) with the Design Science researcher as a professional. They also decide whether research is relevant for their audience, which is a client role. Governments have a role to play as client (setting the agenda), decision maker (about funding), and possibly as witnesses for the public. Regulatory Agencies primarily could play a witness role.

By taking these narrower role definitions, all of the other roles broadly defined above as potentially being played by the rest of the public and humanity are only 
indirectly affected by or involved with DSR. Future clients benefiting from new solution technology usage, future decision makers about new solution technology usage, future professionals employing/deploying new solution technologies, future witnesses for those affected by the usage of new solution technologies, and those potentially affected in the future by the application of new solution technologies, but not involved in their deployment/use need witnesses to protect their interests. Having witnesses for the public, as in the narrow definition and approach, rather than open participation by the public, seems more realistic and practicable.

This, however, leaves a few key questions. First, how should the interests of society/humanity be represented in the design science research process, i.e., who should legitimately witness for the public and how? Second, what should guide these decisions? Third, what are the obstacles to making such decisions and ensuring that the many interests of the public are legitimately represented during DSR?

\subsection{How Should the Public/Humanity Be Consulted, Involved, or Witnessed for?}

As suggested above, one possibility is that it could be the researcher who fills the witness role by understanding and/or imagining what effects the solution means might have on others. However, is the researcher capable of doing this? The question is one of expertise and ability, but also of legitimacy. This might be considered more appropriate where the researcher actually is personally confronted with the same problem(s) that he or she is trying to solve. However, the researcher's personal interest will likely be narrow and not representative of the breadth of different interests held by the diverse members of the public.

Another possibility is that the public's interests can be represented by the community of experts, including not only the researcher, but ethics review and approval bodies, funding agencies, reviewers, editors, and the like. For example, university ethics committees, reviewers, or editors might consider the potential longterm consequences of DSR outcomes in use by the public. The expert community brings more expertise and broader knowledge about the needs of others and possible consequences to them to bear. However, is that knowledge broad enough? Is it legitimate to represent the interests of the public?

Another possibility is that the interests of the public are represented through rigourous evaluation of the solution technology before publication. Evaluation is a key activity in DSR. Really rigourous evaluation requires naturalistic evaluation (Venable, 2006b), which requires involving real people with real problems using the real solution technology (Sun and Kantor, 2006). However, evaluation is already down the track and the purpose(s) have already by then been long determined, so this seems inappropriate. Furthermore, questions of appropriate forms of evaluation in DSR are currently under considerable debate in the DSR community (e.g. see Baskerville et al 2007).

A fourth possibility is that representation of the interests of future users naturally follows from their involvement in forms of research such as Action Research. Action research includes real stakeholder involvement in the development of solution(s) of their real problems. As such, it is both Design Practice and Design Research at the same time. However, there is still a possible issue with generalisability of the solution technology because the worldview of the action research client and their problem(s) 
may be too narrow, idiosyncratic, and not representative of the interests of the public. Furthermore, the choice and inclusion of clients may be opportunistic and ad hoc, leading to a lack of representativeness.

A fifth possibility is that the interests of future users of the solution technology should be represented by government, who funds much of research and is commonly involved in driving the goals influencing competitive grant funding and selection. However, not all of DSR is funded in such a way and much DSR may be little influenced by government.

The final possibility considered here (there may be others) is some form of direct participation by and involvement of the public. Focus groups might be conducted to gather information about needs. Surveys might be conducted. Advisory boards might be created to advise DSR projects. Other forms of broader participation might be created, such as public forums, online discussion groups, and open calls for participation.

While this last possibility would seem to be the most legitimate, there would still be important questions and issues. Importantly, which public do we mean by "the public"? Do we mean the local community or municipality, the state, the country, the region, or the whole world? What about other cultures, countries, etc.? In today's global economy, with global education and global dissemination of ideas, what is published in one context may be used in other contexts for which it was not intended or designed. Should those alternative cultures and societies have their interests and peculiarities of worldview and need be represented in some way? Or can we design for one community and culture and let other communities and cultures decide for themselves whether new solution technologies are appropriate for their context or not (Caveat emptor!)?

Another important question is what should guide decisions about how to represent the needs of the public from among the different possibilities described above. An important issue in answering this question is the amount of resources required to represent the interests of the public and whether they are well spent. One could say that the cost and resources used must be balanced against the need and risk. What is the importance and significance of the problem? Who is affected by it and what are the costs? What are the potential impacts - how widespread or serious? What are the risks to the public? Are there any issues of ethics of the research method and conduct? How important and serious are they? Are there other factors that should be considered? One can also ask whether such questions can even be answered a priori. To some extent, the answers can't be predicted reliably and aren't known until after the research is conducted.

A final question for this paper concerns the practicality and applicability of this whole discussion. Is it possible to influence and change the way that DSR is conducted in order to accommodate the above concerns? There are a number of factors that argue against Design Science researchers accepting any of these ideas and putting them into practice. First, there is the issue of the effort required to learn about these issues, to reflect on them, and to change one's practice. Second, researchers will naturally worry that choosing to involve other stakeholders will take additional (very precious) time and thereby reduce their research productivity. For example, processes to obtain ethical approval may become bureaucratic and time consuming. Third, the values, goals, and objectives of those in other roles, not to mention the approach 
taken, may lead to solutions and work that are different from the vision and designs already held by, created by, and of interest to the researcher. Fourth, any outcome that is different may be less publishable than what the researcher intended to do, so there is less control over outcomes. Finally, if others are involved, the researcher may receive less credit due to the shared effort in the design of a new approach. For these reasons, Design Science researchers may naturally resist accommodating the witnessing activity in their DSR efforts.

\section{Summary and Conclusions}

This paper has applied the Critical System Heuristics perspective to critically analyse Design Science Research. Doing so has raised some issues concerning the way in which DSR should and could be legitimately conducted. The analysis has shown that future clients, decision makers, professionals, and other non-included stakeholders in the future employment of new solution technologies to be invented via DSR, who may potentially be any member of the public or humanity, may well need to have their interests represented by witnesses during DSR. However, there are open questions about the form by which the witness activity should be undertaken and how the resource costs for that activity can be balanced against the interests of and risks to the public. Further, there are questions about who constitute the public that needs to be witnessed for, with the answers ranging from only locally affected groups through all of humanity, including people in other countries and cultures. Finally, there are open questions about how the recommended inclusion of a witness role and activity can be raised, accepted, and included in DSR as practiced.

\section{References}

Baskerville, R., Pries-Heje, J., Venable, J.: Soft Design Science Research: Extending the Boundaries of Evaluation in Design Science Research. In: Chatterjee, S., Rossi, M. (eds.) Proceedings of the 2nd International Conference on Design Science Research in Information Systems and Technology (DESRIST 2007), Pasadena, California, USA, May 13-15 (2007)

Baskerville, R., Vaishnavi, V. (eds.): Proceedings of the 3rd International Conference on Design Science Research in Information Systems and Technology (DESRIST 2008), Atlanta, Georgia, USA, May 7-9, 2008 (2007)

Cecez-Kecmanovic, D., Klein, H.K., Brooke, C.: Exploring the Critical Agenda in Information Systems Research. Information Systems Journal 18(2), 123-135 (2008)

Chatterjee, S., Rossi, M. (eds.): Proceedings of the 2nd International Conference on Design Science Research in Information Systems and Technology (DESRIST 2007), Pasadena, California, USA, May 13-15 (2007)

Checkland, P.: Systems Thinking, Systems Practice. John Wiley \& Sons, Chichester (1981)

Checkland, P., Holwell, S.: Information, Systems and Information Systems. John Wiley \& Sons, Chichester (1998)

Checkland, P., Scholes, J.: Soft Systems Methodology in Action. John Wiley \& Sons, Chichester (1990)

Cranefield, J., Yoong, P.: To Whom Should Information Systems Research Be Relevant: The Case for an Ecological Perspective. In: Österle, H., Schelp, J., Winter, R. (eds.) Proceedings of the 15th European Conference on Information Systems (ECIS 2007, on CD), St Gallen, Switzerland, 7-9 June 2007, pp. 1313-1324 (2007) 
Emery, M. (ed.): Participative Design for Participative Democracy. Centre for Continuing Education. Australian National University, Canberra (1989)

Gregor, S., Jones, D.: The Anatomy of a Design Theory. Journal of the Association for Information Systems 8(5), article 2, 312-335 (2007)

Habermas, J.: Moral Consciousness and Communicative Action. MIT Press, Cambridge (1983) (English translation 1991)

Hevner, A., Chatterjee, S. (eds.): Proceedings of the 1st International Conference on Design Science in Information Systems and Technology (DESRIST 2006),, Claremont, California, USA, February 24-26, 2005 (2006),

http://ncl.cgu.edu/firstdesignconf/Cochairmsg.htm (viewed 18 June 2007)

Hevner, A.R., March, S.T., Park, J., Ram, S.: Design Science in Information Systems Research. MIS Quarterly 28(1), 75-105 (2004)

Keen, P.: Relevance and rigour in information systems research: Improving quality, confidence, cohesion and impact. In: Nissen, H.-E., Klein, H.K., Hirschheim, R. (eds.) Information Systems Research: Contemporary Approaches and Emergent Traditions (Proceedings of the IFIP WG 8.2 Working Conference in Copenhagen), pp. 27-49. North-Holland, Amsterdam (1991)

Kyng, M., Beardon, C., Mathiassen, L. (eds.): Computers and Design in Context. MIT Press, Cambridge (1997)

March, S.T., Smith, G.F.: Design and Natural Science Research on Information Technology. Decision Support Systems 15(4), 251-266 (1995)

Mitchell, R.K., Agle, B.R., Wood, D.J.: Toward a Theory of Stakeholder Identification and Salience: Defining the Principle of Who and What Really Counts. Academy of Management Journal 22(4), 853-886 (1997)

Moody, D.: Building links between IS research and professional practice: improving the relevance and impact of IS research. In: Proceedings of the Twenty First International Conference on Information Systems, Brisbane, Queensland, Australia, pp. 351-360 (2000)

Moody, D., Buist, A.: Improving Links Between Information Systems Research and Practice Lessons from the Medical Profession. In: Proceedings of the 10th Australasian Conference on Information Systems, Wellington, New Zealand, pp. 645-659 (1999)

Mumford, E.: Designing Human Systems: The ETHICS Method. Manchester Business School (1983)

Mumford, E.: Systems Design: Ethical Tools for Ethical Change. Macmillan, London (1996)

Mumford, E.: The Story of Socio-Technical Design: Reflections on its successes, failures and potential. Information Systems Journal 16, 317-342 (2006)

Nunamaker Jr., J.F., Chen, M., Purdin, T.D.M.: Systems Development in Information Systems Research. Journal of Management Information Systems 7(3), 89-106 (1991)

Schuler, D., Namioka, A.: Participatory Design: Principles and Practices. Lawrence Erlbaum Associates, Mahwah (1993)

Stahl, B.C.: The Ethical Nature of Critical Research in Information Systems. Information Systems Journal 18(2), 137-163 (2008)

Sun, Y., Kantor, P.B.: Cross-Evaluation: A new model for information system evaluation. Journal of the American Society for Information Science and Technology 57(5), 614-628 (2006)

Ulrich, W.: Critical Heuristics of Social Planning: A New Approach to Practical Philosophy. Paul Hapt, Bern/Stuttgart (1983)

Ulrich, W.: Critical Heuristics of Social Systems Design. European Journal of Operational Research 31, 276-283 (1987) 
Ulrich, W.: Critical Systems Heuristics. In: Daellenbach, H.G., Flood, R.L. (eds.) The Informed Student Guide to Management Science. Thomson Learning, London (2002)

Vaishnavi, V., Kuechler, B.: Design Research in Information Systems. in ISWorldNet website (2004),

http://www.isworld.org/Researchdesign/drisISworld.htm (viewed 9 January 2006)

Venable, J.R.: The Role of Theory and Theorising in Design Science Research. In: Hevner, A., Chatterjee, S. (eds.) Proceedings of the 1st International Conference on Design Science in Information Systems and Technology (DESRIST 2006), Claremont, California, USA, February 24-26 (2006a),

http://ncl.cgu.edu/firstdesignconf /

DESRIST\%202006\%20Proceedings/2A_1.pdf (viewed June 18, 2007)

Venable, J.: A Framework for Design Science Research Activities. In: Proceedings of the 2006 Information Resource Management Association Conference, Washington, DC, USA (2006b)

Walls, J.G., Widmeyer, G.R., El Sawy, O.A.: Building an information system design theory for vigilant EIS. Information Systems Research 3(1), 36-59 (1992) 